\title{
PENGEMBANGAN PARIWISATA BERBASIS ALAM OLEH MASYARAKAT DESA GONDORIYO SEMARANG UNTUK PENINGKATAN PEREKONOMIAN WARGA
}

\author{
Tasya Salsabila \\ Universitas Islam Negeri Walisongo Semarang \\ tasya_1807016042@student.walisongo.ac.id
}

\begin{abstract}
The writing of this article is intended to explain the development of tourism by villagers in Gondoriyo to improve the welfare of citizens. The method for updating this article is to read various references in scientific journals that discuss the development of bases to improve citizens' finances, then analyze them and present them systematically in this article. The results of this article discuss the topics, namely: 1) The origins of the development of the Gondoriyo waterfall 2) The role of the community in the development of the Gondoriyo waterfall 3) Obstacles in the development of the Gondoriyo waterfall 4) The benefits of the development of the Gondoriyo waterfall for the development of the Gondoriyo welfare village. Based on the results of a study submitted by the villagebased community developer Gondoriyo is very effective to improve the economy of citizens.
\end{abstract}

Keyword: tourism, economic, improvement

\section{PENDAHULUAN}

Konvergensi pertumbuhan pariwisata yang pesat dalam kemiskinannegara telah memicu gelombang minat besar dalam pariwisata sebagai strategi pembangunan yang berkelanjutan untuk memenuhi tujuan yang berpihak pada masyarakat miskin.(Chok, Macbeth, \& Warren, 2007) Pada akhir 1990an, Departemen Inggris untuk Pembangunan Internasional (DFID) mengusulkan konsep pro-poor pariwisata (PPT) dan menyarankan agar strategi PPT harus diarahkan menuju menghasilkan manfaat bersih bagi masyarakat miskin (DfID, 1999). Para pemangku kepentingan yang terlibat dalam PPT menunjukkan berbagai latar belakang dan posisi nilai. Hubungan antara pariwisata dan pengurangan kemiskinan telah menjadi masalah memecah belah (Njoya \& Seetaram, 2018).

Banyak penelitian
mengembangkan model teoritis untuk
menunjukkan efek positif pariwisata (Gascón,
2015). Misalnya, rumah tangga miskin

meningkatkan pendapatan melalui langsunga tau partisipasi tidak langsung dalam pariwisata. Pariwisata juga membantu memperluas pajak pangkalan pemerintah daerah dan nasional; peningkatan pendapatandapat digunakan untuk menyediakan atau meningkatkan sosial, budaya, dan lingkungan alami orang miskin. Secara umum, pariwisata dapat memberikan mampu mencapai hasil jangka pendek dan jangka menengah bagi masyarakat miskin melalui dua saluran, yaitu pendapatan dan pajak (Yu, Wang, \& Marcouiller, 2019).

Wisata pedesaan adalah tentang nilainilai dan penegasan kembali tradisi, tetapi lebih dari itu: pariwisata juga menerapkan minat pada pembangunan pedesaan dan arsitektur. Wisata pedesaan menyangkut perlindungan kesehatan, kesejahteraan yang diekspresikan dalam kesenangan hidup, kualitas udara dan air; makanan asli dan sehat di fasilitas ramah lingkungan dan pedesaan yang digunakan sebagai sumber kepuasan dan bersantai. Green Building berarti membangun 
TASYA SALSABILA

Pengembangan Pariwisata Berbasis Alam Oleh Masyarakat Desa Gondoriyo Semarang Untuk Peningkatan Perekonomian Warga

dengan tujuan memastikan kesejahteraan rakyat, yang dianggap sebagai kondisi fisik dan mental di mana kesehatan individu,sosialkeseimbangan ekonomi, dan perlindungan lingkungan berperan (D'Alessandro, 2016). Masyarakat memanfaatkan curug Gondoriyo sebagai salah satu untuk meningkatkan perekonomian di desanya. Dengan cara mengubah sebuah alas dan air limbah menjadi tempat wisata yaitu curug Gondoriyo. Bukan hanya wisata alam saja masyarakat juga menyediakan wisata kuliner yang berupa makanan khas dari Desa Gondoriyo yaitu nasi bleduk dan wedang sinom.

Pariwisata saat ini memiliki masalah. Ini kecanduan pertumbuhan dan mungkin perluuntuk ditempatkan dalam program pemulihan 12 langkah, mirip seperti itu dibuat oleh Alcoholics Anonymous. Mengikuti metafora ini, yang pertamaLangkah mengakui masalah. Periksa situs web pariwisata pemerintah,hampir tanpa kecuali, dan poin ini akan diilustrasikan. Untuk pendirian, seperti negara Australia memiliki strategi "Pariwisata 2020", itu memfokuskan pemerintah dan industri pada strategi pertumbuhan yang menargetkan "...lebih dari \$ 115 miliar dalam pengeluaran semalam pada tahun 2020 (naik dari \$ 70 miliardi 2009)" (Tourism Australia, 2017). Dengan mantra pertumbuhan, strategi memanfaatkan para pemain ini dalam suatu program untuk menumbuhkan permintaan, mengurangi "beban pengaturan" dan meningkatkan akses transportasi dan infrastruktur untuk meningkatkan jumlah pengunjung. Hampir hilang adalah hari-hari ketika otoritas pariwisata dapat mendukung pariwisata yang diarahkan untuk pendidikan, sosialmembawa dengan baik, inklusi dan tujuan non-ekonometrik lainnya. Ini tepat waktu saat untuk mempertimbangkan kembali kemungkinan untuk pariwisata berkelanjutan di ini PBB mendeklarasikan Tahun Internasional Pariwisata Berkelanjutan untuk pengembangan (Higgins-Desbiolles, 2018). Misalnya seperti, negara berkembang salah satunya negara Indonesia khususnya desa
Gondoriyo, Semarang memanfaatkan wisata curug Gondoriyo untuk meningkatkan perekonomian desa tersebut dan untuk meningkatkan minat wisatawan lokal dan wisatawan asing. Maka perlunya meningkatkan akses transportasi dan infrastruktur, agar mudah mengakses wisata curug tersebut.

Dalam ekonomi baru, semua inovasi yang dibawa oleh era digital memainkan peran penting. Dalam ekonomi baru, perantara antara produsen dan konsumen akan menghilang bersama dengan jaringan komunikasi digital. Perusahaan perantara tidak akan mengambil fungsi baru dan akan kehilangan validitasnya jika mereka tidak memberikan nilai baru kepada mereka.

Internet berkembang dan berubah dengan cepat dengan menyediakan Internet untuk mencari dan memesan produk perjalanan online. Banyak perusahaan, seperti Airbnb dan Uber, beralih dari model bisnis tradisional ke model konsumen-ke-konsumen. Untuk memenuhi kebutuhan pelanggan, industri pariwisata, dengan menciptakan platform baru dan inovatif; ini bertujuan untuk menciptakan solusi inovatif dengan menggabungkan uang, teknologi, dan pengetahuan (Colombo \& Baggio, 2017). Berbelanja di internet adalah kebiasaan baru. Sementara \$ 289 miliar dihabiskan untuk perdagangan elektronik pada 2012, itu tidak terbayangkan bagi konsumen untuk membeli sesuatu dari internet pada awal 1990-an. Kelahiran perdagangan online didasarkan pada 1994 dengan album menyengat \$12,48 dari situs Netmarket dari pertukaran aman pertama (Lewis, 1994).

Namun saat ini, belanja di internet menjadi sangat umum dan tingkat penggunaannya meningkat setiap tahun. Menurut Survei Penggunaan Teknologi Informasi Rumah Tangga (TI) 2018 TUIK, jumlah orang yang berbelanja di internet telah meningkat menjadi 17 juta 580 ribu. Ini berarti ada peningkatan 2,7 juta di internet. 
Tingkat pembeli tahun sebelumnya adalah 24,9 .

Sekarang, bisnis untuk menangkap era Industri 4.0, digitalisasi, pengkodean dan perangkat lunak akan meningkatkan pentingnya masalah tersebut. Untuk alasan ini, pengembangan nilai-nilai baru ini akan sangat penting dalam kemajuan perusahaan pariwisata yang berorientasi konsumen. Peningkatan belanja internet memberikan arah baru bagi perekonomian dan mengarahkan semua perusahaan untuk fokus pada proses digitalisasi ini. Tujuan dari penelitian ini adalah untuk menentukan penggunaan dan efek dari teknologi baru dan mata uang kripto di sektor pariwisata.

Potensi pariwisata untuk mendorong pertumbuhan ekonomi menjadikannya alat yang relevan untuk mengembangkan masyarakat berpenghasilan rendah dan kurang terlayani, dan menempatkan di pusat pengembangan pariwisata (Scheyvens, 2002). Pekerjaan sebelumnya menyiratkan bahwa masyarakat yang membutuhkan memiliki yang diperlukan aset pariwisata, berikan pengalaman lokal yang dicari turis dan membangun ruang yang mereka konsumsi (Beeton, 2006). Ini mengarah pada tujuan mengembangkan masyarakat secara holistik dan berkelanjutan, sering melalui pariwisata berbasis masyarakat dan berpihak pada masyarakat miskin yang ditujukan untuk menyediakan kekayaan ekonomi dan sosial yang regeneratif, termasuk manfaat vironmental (Aquino, Lück, \& Schänzel, 2018). Wisata Curug Gondoriyo juga menggunakan tenologi berupa menggunakan lampu warna - warni yang dipasang disekitar curug agar menambang estetika Curug Gondoriyo dan mereka mempromosikan Curug Gondoriyo melalui sosial media

\section{METODE PENELITIAN}

Penelitian artikel ini dilakukan dengan cara menelusuri berbagai artikel ilmiah di jurnal, mengobservasi langsung ke tempatnya dan melakukan wawancara dengan warga Desa Gondoriyo yang sekaligus berperna penting dalam mewujudkan pembangunan di Desa Gondoriyo.

\section{HASIL PENELITIAN DAN PEMBAHASAN}

Asal usul dari curug ini memang sudah dari jaman nenek moyang curug tersebut sudah ada. Sudah ada kunjungan dari mahassiswa dari mana pun instansi dan lainlain. Masyarakat setempat menyepelekan adanya curug tersebut. Masyarakat beranggapan curug tersebut hanya sementara waktu berjalannya. Seiring berjalannya waktu tahun 2017-2018 di gaung-gaungkan untuk wisata curug gondoriyo. di nasional dan khususnya di kota Semarang. Pada tanggal 30 juli 2018 masyarakat di SK-kan secara tertulis. Dikarenakan sudah ada SK resmi maka masyarakat mengadakan launching. Tetapi launching tersebut harus dihadiri oleh orang nomor satu di kota Semarang yaitu Walikota Semarang. Launching tersebut tidak berjalan dengan lancar masyarakat mengalami kegagalan tiga kali launching dikarenakan menyesuaikan jadwal Walikota Semarang. Pada saat launching masyarakat berusaha berpartisipasi untuk menyukseskan acara tersebut dikarenakan dihadiri oleh walikota Semarang. Baru launching pada 9 Februari 2019. Kalau secara SK diresmikan pada tahun 2018.

Salah satu panitia pembentukan pembangunan Curug Gondoriyo adalah ibu Suciyati. Lalu diikut sertakan lomba tentang pariwisata dari kearifan lokalnya memang semuanya murni dari swadaya masyarakat. Awalnya desa gondoriyo merupakan hutan hutan. Dengan adanya PokDarWis (Kelompok Sadar Wisata) dan tokoh masyarakat. Melakukan musyawarah untuk menentukan nama curug yang ada disekitar desa gondoriyo. Awalnya mau dinamakan curug wedus dikarenakan pernah ada wedus atau kambing jatuh ke dalam curug tersebut. Tetapi 
TASYA SALSABILA

Pengembangan Pariwisata Berbasis Alam Oleh Masyarakat Desa Gondoriyo Semarang Untuk Peningkatan Perekonomian Warga

dalam musyawarah tersebut nama wedus dianggap kurang etis. Agar mengangkat nama desa maka dinamakanlah Curug Gondoriyo. Kalau di lihat- lihat warna air curugnya itu keruh dikarenakan memanfaatkan air limbah. SDM nya bisa dikatakan masih rendah sehingga belum sampai pengolahan baru sampai ke pemanfaatan, mereka beranggapan bahwa SDM di Kota dan di Desa itu berbeda. Jadi masyarakat mengambil konsep untuk mengabadikan moment di curug tersebut karena air curug tersebut berasal dari air limbah maka wisatawan tidak disarankan untuk mandi di curug tersebut.

Curug tersebut memanfaatkan air limbah maka dari itu masyarakat berinovasi untuk menarik wisatawan dengan cara menambah estetika air curug tersebut dengan menambahkan lampu yang berwarna-warni di sekitar curug tersebut sehingga curug tersebut di buka pada malam hari. Pada awalnya, curug tersebut hanya tempat untuk pemancingan, membuang air besar, mandi, mencuci dll. Lalu masyarakat berusaha untuk bersoalisasi ke rumah - rumah agar tidak mengandalkan air curug tersebut untuk sumber kehidupan dan memohon kepada warga untuk berpartisipasi dengan memberikan sebuah tanaman dan juga meminta bantuan ke LPMK, F3G lalu mengundang beberapa organisasi untuk diberikan informasi seputar adanya curug tersebut. Masyarakat sekitar juga bekerja bakti dengan Katana (Kelurahan Tanggung Bencana) dan berbagai macam forum dengan berjumlah delapan. Curug tersebut memang sudah terlihat secara alami tetapi KopDarWis menambah estetika dengan cara meminta ibu ibu PKK membawa tanaman - tanaman hias.

Dengan adanya Curug Gondoriyo, masyarakat memanfaatkannya dengan berjualan disekitar Curug tersebut, maka perekonomian masyarakat dapat berkembang karena adanya Curug Gondoriyo. KopDarWis juga memanfaatkannya dengan mengolah pangan yang dinamakan "Nasi Bladeg" yang asal usulnya Bladeg adalah semburan api yang dikeluarkan pada saat memasak memakai kayu bakar yang dibungkus dengan daun pisang dan daun jati dengan bentuk yang semenarik mungkin. Ada juga wedhang Sinom, dengan asal usul nama Kota Semarang yang berarti Aseme Arang - Arang lalu masyarakat membuat wedhang sinom yang artinya memakai daun muda yang diolah oleh masyarakat sekitar yang dikemas menggunakan bambu berbentuk gelas serta sedotan dari bambu.

Ada kendala pro dan kontra antar masyarakat karena Gondoriyo memiliki sekitar 12 RW, ada beberapa masyarakat menganggap curug Gondoriyo tersebut hanya dimiliki oleh masyarakat yang tinggal di sekitar Curug tersebut padahal curug tersebut menggunakan nama wilayah Gondoriyo sedangkan Gondoriyo mencakup banyak RW yang seharusnya $12 \mathrm{RW}$ berperan aktif dalam pembangunan curug. Tetapi masyarakat yang tidak peduli dengan adanya curug tersebut mengharuskan KopDarWis masuk ke beberapa lembaga - lembaga untuk meminta bantuan pembangunan seperti datang kerumah - rumah warga untuk mengajak warga berpartisipasi seperti memberikan sebuah tanaman. Ada lagi kendala yaitu penerangan yang kurang sehingga wisatawan enggan datang ke curug tersebut dikarena kurangnya pencahayaan. Jalan menuju curug juga pada saat itu masih berupa tanah belum ada paving sehingga menyulitkan wisatawan datang, serta penunjuk arah yang kurang jelas dan aplikasi Google Maps mengarahkan jalan yang tidak sesuai.

Dalam mempromosikan makanan khas daerah gondoriyo juga mengalami kendala dalam mempromosikan ke berbagai wisatawan karena masyarakat setempat masih banyak yang Gagap Tekhnologi sehingga banyak wisatawan tidak mengetahui, dalam pengemasan belum menarik dan pemberian nama brand. lalu mengolah dengan bahan pokok yaitu singkong, dibuat dengan berbagai macam tetapi konsep tersebut sudah dilakukan oleh Kampung Jawi yang dimana kampung tersebut terletak didekat di daerah curug. 
Sayangnya, Kampung Jawi lebih dulu launching dan kampung tersebut tidak mau diajak bekerja sama oleh KopDarWis karena menyepelekan adanya curug itu.

Awalnya, curug tersebut belum tersentuh oleh Pemerintah lalu KopDarWis menggunakan dana iuran dan pinjaman dari Bank untuk pembangunan Curug tersebut. Setelah Walikota Semarang datang dan menanyakan apa saja yang dibutuhkan lalu panitia KopDarWis memberi informasi bahwa masih terkendala pada akses jalan. Setelah mengetahui adanya curug tersebut, Pariwisata semarang ingin membeli curug tersebut, tetapi KopDarWis menolak, karena jika curug Gondoriyo dibeli oleh Pemerintah maka masyarakat tidak bisa berinovasi dan masyarakat akan tersingkirkan dan akan merugikan masyarakat yang ada di sekitar Curug.

Panitia KopDarWis tidak ingin meminta - minta dana seperti halnya 'mengemis' karena mereka beranggapan hal semacam ini adalah kesadaran dari masing - masing individu bagaimana caranya untuk melestarikan lingkungan yang ada di daerah Gondoriyo. Panitia KopDarWis juga berharap kepada anak millennial untuk merawat dan menjaga kelestarian lingkungan yang masih alami ini.

\section{KESIMPULAN}

Berdasarkan uraian pembahasan artikel ini, penulis menyimpulkan sebagai berikut. Wisata pedesaan adalah tentang nilai-nilai dan penegasan kembali tradisi, tetapi lebih dari itu: pariwisata juga menerapkan minat pada pembangunan pedesaan dan arsitektur. Wisata pedesaan menyangkut perlindungan kesehatan, kesejahteraan yang diekspresikan dalam kesenangan hidup, kualitas udara dan air; makanan asli dan sehat di fasilitas ramah lingkungan dan pedesaan yang digunakan sebagai sumber kepuasan dan bersantai.

Misalnya seperti, negara berkembang salah satunya negara Indonesia khususnya desa Gondoriyo, Semarang memanfaatkan wisata curug Gondoriyo untuk meningkatkan perekonomian desa tersebut dan untuk meningkatkan minat wisatawan lokal dan wisatawan asing. Maka perlunya meningkatkan akses transportasi dan infrastruktur, agar mudah mengakses wisata curug tersebut.

Potensi pariwisata untuk mendorong pertumbuhan ekonomi menjadikannya alat yang relevan untuk mengembangkan masyarakat berpenghasilan rendah dan kurang terlayani, dan menempatkan di pusat pengembangan pariwisata (Scheyvens, 2002). Pekerjaan sebelumnya menyiratkan bahwa masyarakat yang membutuhkan memiliki yang diperlukan aset pariwisata, berikan pengalaman lokal yang dicari turis dan membangun ruang yang mereka konsumsi (Beeton, 2006).

\section{DAFTAR PUSTAKA}

Aquino, R. S., Lück, M., \& Schänzel, H. A. (2018). A conceptual framework of tourism social entrepreneurship for sustainable community development. Journal of Hospitality and Tourism Management, 37, 23-32.

Beeton, S. (2006). Community development through tourism. Landlinks Press.

Chok, S., Macbeth, J., \& Warren, C. (2007). Tourism as a tool for poverty alleviation: A critical analysis of 'propoor tourism'and implications for sustainability. Current Issues in Tourism, 10(2-3), 144-165.

Colombo, E., \& Baggio, R. (2017). Tourism distribution channels: Knowledge requirements. In Knowledge transfer to and within tourism: Academic, industry and government bridges (pp. 289-301). Emerald Publishing Limited.

D'Alessandro, F. (2016). Green building for a green tourism. A new model of ecofriendly agritourism. Agriculture and 
TASYA SALSABILA

Pengembangan Pariwisata Berbasis Alam Oleh Masyarakat Desa Gondoriyo Semarang Untuk Peningkatan Perekonomian Warga

Agricultural Science Procedia, 8, 201210.

DfID. (1999). Tourism and poverty elimination: Untapped potential. Department for International Development London.

Gascón, J. (2015). Pro-Poor Tourism as a Strategy to Fight Rural Poverty: A Critique. Journal of Agrarian Change, 15(4), 499-518.

Higgins-Desbiolles, F. (2018). Sustainable tourism: Sustaining tourism or something more? Tourism Management Perspectives, 25, 157-160.

Lewis, P. H. (1994). Attention shoppers: Internet is open. The New York Times, 1 .

Njoya, E. T., \& Seetaram, N. (2018). Tourism contribution to poverty alleviation in Kenya: A dynamic computable general equilibrium analysis. Journal of Travel Research, 57(4), 513-524.

Scheyvens, R. (2002). Tourism for development: Empowering communities. Pearson Education.

Yu, L., Wang, G., \& Marcouiller, D. W. (2019). A scientometric review of propoor tourism research: Visualization and analysis. Tourism Management Perspectives, 30(January), 75-88.

https://doi.org/10.1016/j.tmp.2019.02.005

Tourism Australia (2017). Tourism 2020. Retrieved from 20 October .

http://www.tourism.australia.com/en/about/ou r-organisation/our-performance-andreporting/tourism-2020.html 